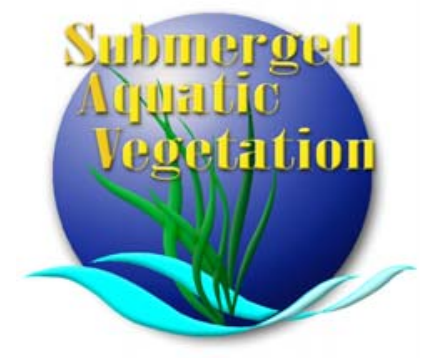

\title{
Restoring Eelgrass (Zostera marina) from Seed: A Comparison of Planting Methods for Large-Scale Projects
}

by Robert Orth, Scott Marion, Steven Granger, and Michael Traber

PROBLEM: Eelgrass (Zostera marina) seeds are being used in a variety of both small- and large-scale restoration activities and have been successfully used to initiate recovery of eelgrass in the Virginia seaside coastal lagoons, which lost eelgrass in the 1930s 'wasting disease' pandemic (Orth et al. 2006a). However, a major bottleneck with the use of seeds has been the relatively low rate of seedling establishment, generally 10 percent or less of seeds placed in the field (Orth et al. 2003). A recently developed underwater seed planter (Traber et al. 2003) represents an alternative method that could improve seedling success compared to techniques used in previous Chesapeake Bay studies and elsewhere.

PURPOSE: The objective of this study was to compare the effectiveness of different techniques of seeding for use in large-scale projects: injecting seeds into submerged sediments with a mechanical seed planter and hand-broadcasting seeds on the sediment surface using divers.

BACKGROUND: Seagrass transplanting projects worldwide have traditionally relied on adult plants (Fonseca et al. 1998) using a variety of manual and mechanical techniques (Fonseca et al. 1998, Fishman et al. 2004, Treat and Lewis 2006). However, most techniques using adult plants are labor-intensive and time-consuming, requiring physical excavation of the donor material, which could be deleterious to the donor bed's survival, especially if annual growth rates are slow. In addition, transporting adult plants can present logistical constraints if the transplant site is located a significant distance from the donor site, or if the methodology requires moving sediment along with the plants. One of the key advantages of transplanting adult plants is the immediate creation of habitat for fauna, which have been shown to colonize these areas rapidly (Fonseca et al. 1996).

Transplant projects incorporating seeds have been relatively rare despite the fact that some species produce large numbers of seeds, ranging up to tens of thousands per square meter (Orth et al. 2006b). Seed production can be temporally and spatially variable and may require expensive facilities to maintain seeds until needed (Granger et al. 2002, Orth et al. 2006a). Recently, seeds have been shown to be important in creation of new patches, recovery of beds lost due to disturbance, and providing genetic diversity (Plus et al. 2003, Orth et al. 2006a), suggesting seagrass seeds could play an important role in seagrass restoration efforts (Orth et al. 2006a, 2006b, 2006c). 


\section{METHODS:}

Study Sites: Three sites were chosen for the comparison test based on results of previous seed experiments and ongoing seagrass restoration efforts (Harwell and Orth 1999, Orth et al. 2003). Two sites were located in Chesapeake Bay: Mumfort Island in the York River, and Burtons Point in the Piankatank River (Figure 1). The third site was located in Spider Crab Bay, one of the coastal bays of the lower Delmarva Peninsula (Figure 1). All sites historically supported dense stands of eelgrass (Orth and Moore 1984) and were at water depths between 0.5 and $1.0 \mathrm{~m}$ (Mean Low Water). All sites were unvegetated at the time of planting and had predominantly sandy sediments (Table 1) (Orth et al. 2003).

Design and Procedure: Three methods of seeding were tested in this experiment. The first method was a mechanical seed planter (Traber et al. 2003), which consisted of a benthic sled that creates furrows into which a seed-gel mixture is extruded and buried by a weighted pad (Figure 2), and a pump that supplies a mixture of eelgrass seeds and suspension gel through flexible tubing to a manifold (distribution) system located on the sled (Figure 3). The gel (Knox ${ }^{\circledR}$ gelatin in this case) provides a viscous medium for pumping and keeps seeds in suspension in the supply chamber, allowing a predictable rate of seed delivery controlled directly by the pump speed (Figure 4) (Traber et al. 2003). The gelatin was prepared just prior to the experiment and kept chilled on ice until mixing with each batch of seeds. This cooling is essential, as the viscosity of the gelatin varies with temperature. The sled buries seeds to a depth of 1-2 cm below the sediment

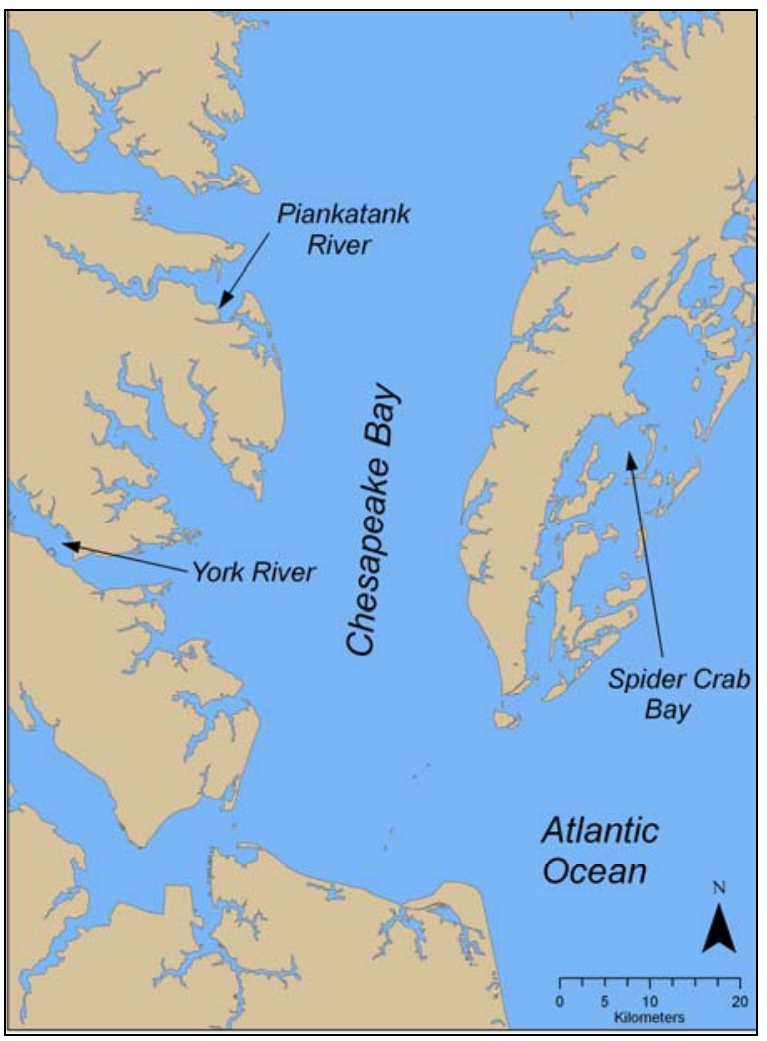

Figure 1. Map of the study areas. surface through eight injectors distributed along its 1-m width (Figure 5). 


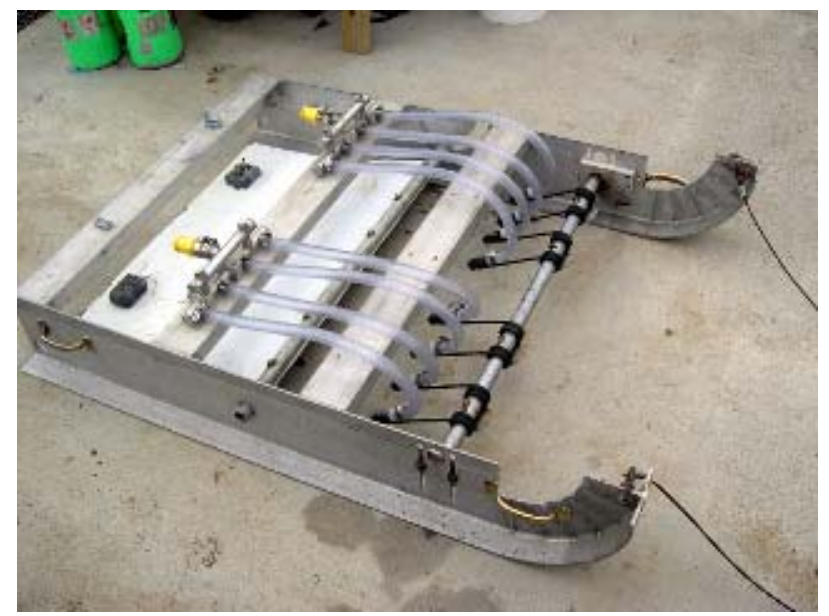

Figure 2. Zostera marina seed planting sled.

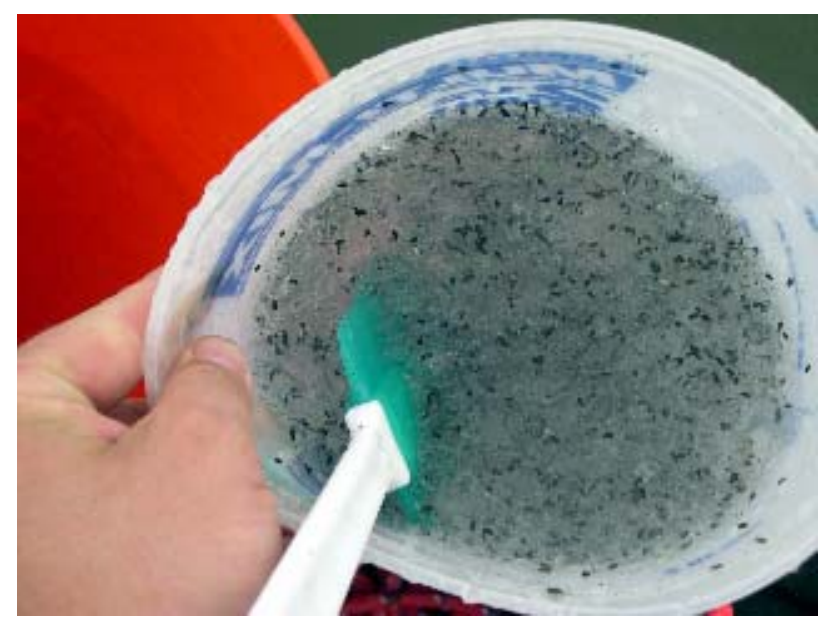

Figure 4. Seeds suspended in gel.

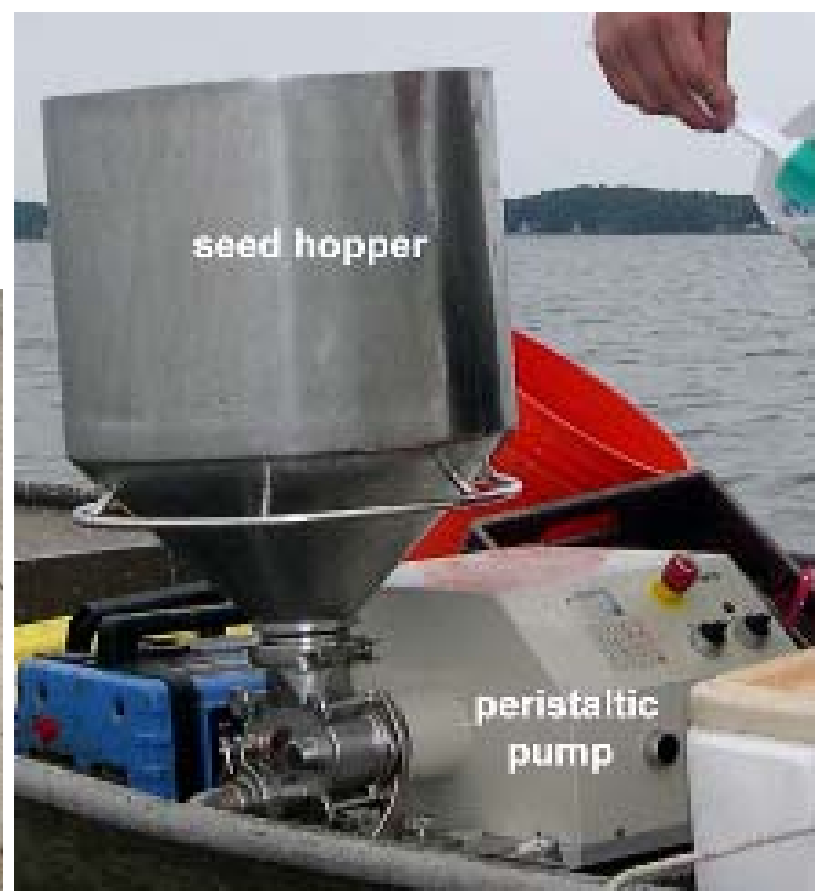

Figure 3. Seed/gel pumping mechanism.

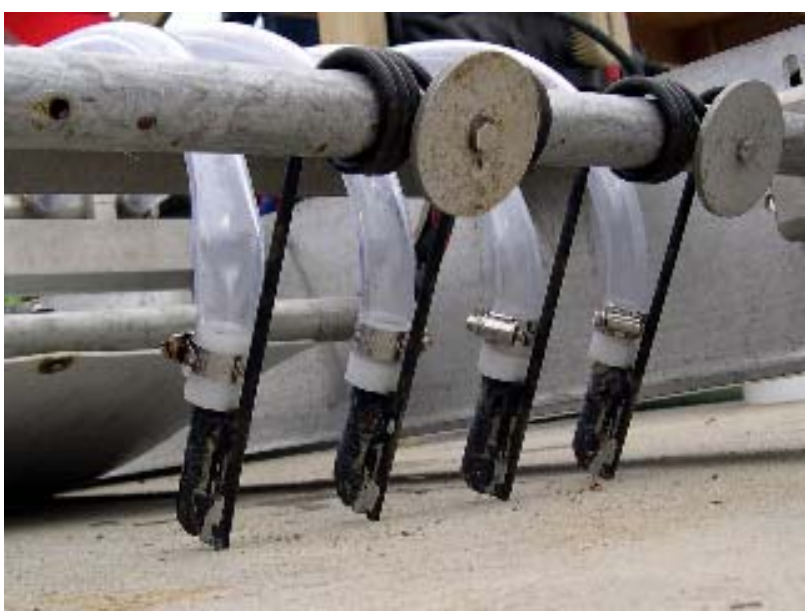

Figure 5. Spring-loaded seed injecting nozzles.

\begin{tabular}{|c|c|c|c|}
\hline Site & $\%$ Sand & $\%$ Silt/Clay & $\%$ Organic \\
\hline York River (Mumfort Island) & $96.6(0.6)$ & $3.4(0.6)$ & $0.62(0.00)$ \\
\hline Piankatank River (Burtons Point) & $98.6(0.5)$ & $1.4(0.5)$ & $0.73(0.07)$ \\
\hline Spider Crab Bay & $86.2(4.6)$ & $13.8(4.1)$ & $1.41(0.36)$ \\
\hline
\end{tabular}


In the second method, seeds were hand broadcast directly on the sediment surface. Seeds on the sediment surface do not move far from where they settle (Orth et al. 1994) and this method has been successfully used in previous seed experiments (Orth et al. 2003) and restoration efforts in the Chesapeake region (Orth et al. 2006a).

A third method was created to test for potential effects of the gel used in the mechanical planter. For this treatment, a diver used a hand-held pipette to inject seeds without any gel below the sediment surface at a similar depth to that achieved by the mechanical planter. Seeds were gently injected into haphazardly placed lines in a 1-m-wide band along the 10-m line.

At each site, six replicates of the three treatments were created, each receiving 3,000 seeds planted in 1-m-wide by 10-m-long strips (designed to match the planting pattern created by the planting sled). Replicates were positioned randomly in two rows of nine strips, with $10 \mathrm{~m}$ between parallel strips and $20 \mathrm{~m}$ between rows. To establish the machine test strips, the pump was placed in a johnboat and pulled along the 10-m strip by a winch on an anchored boat, with the sled towed directly behind the johnboat (Figure 6). For broadcast strips, seeds were scattered by a diver along the entire strip. For the hand-buried seeds, small batches of seeds were pipetted into multiple linear rows along the $10-\mathrm{m}$ plot, roughly simulating the pattern created by the machine.

Seeds were harvested by hand collecting mature reproductive shoots with viable seeds from established beds in late May 2005. Seeds are generally released from the flowering shoots from mid-May into early June in Chesapeake Bay. Harvested shoots were placed in nylon mesh bags, returned to the laboratory, and placed in flow-through, circular, $3.8-\mathrm{m}^{3}$ outdoor tanks that were shaded (approximately 50 percent) and aerated. Shoots were maintained in the tanks for up to 8 weeks until mid- to late July to allow for decom-

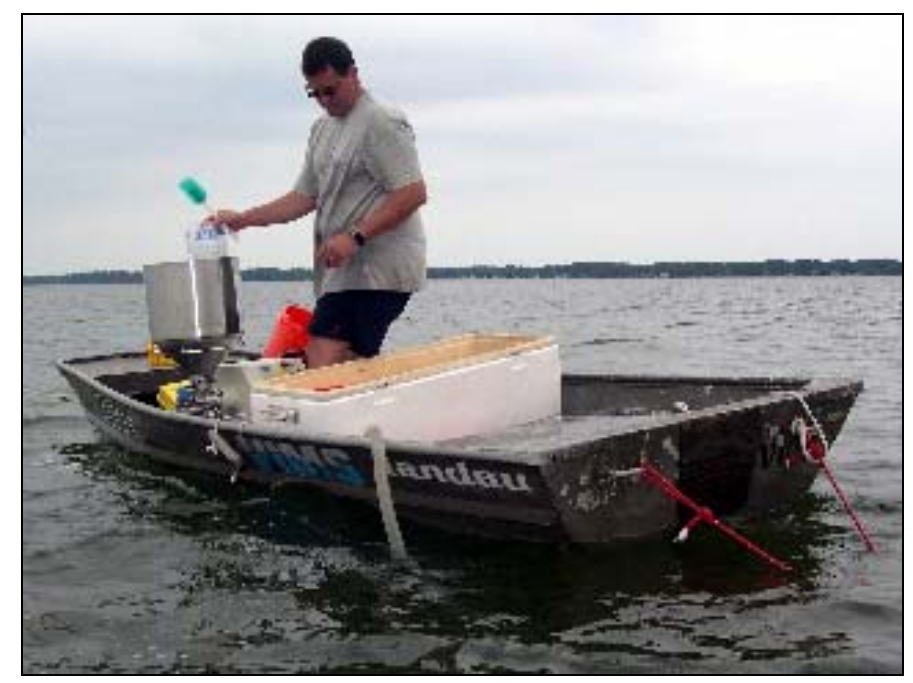

Figure 6. Pumping seeds to the deployed planting sled. position of the shoots and release of seeds. Remaining stem and leaf material was removed by sieving. Harvested seeds were then kept in aerated re-circulating tanks held at ambient water temperatures and salinity. Seed planting occurred in September 2005, prior to the initiation of seed germination in the late fall (Orth and Moore 1983, Moore et al. 1993). Seed viability was assessed by planting three replicate batches of 10 seeds 5-7 mm deep in seived natural sediment. Sediment containers were held inside a greenhouse in flow-through seawater at ambient water temperatures. Germination was assessed in January (when germination was complete) by sieving the sediment and retrieving all 
planted seeds. The seed source used in this experiment exhibited 53 percent germination, somewhat lower than the maximum rates achieved in the lab in past years (80-90 percent), but substantially higher than rates observed in the field in this and other experiments conducted in 2005.

Seedlings were assessed in April 2006, when they could be most accurately counted by divers. A $4-\mathrm{m}^{2}$ quadrat divided into $16-$ to $0.25-\mathrm{m}^{2}$ cells was placed at the beginning of each line and all seedlings were recorded in each $0.25-\mathrm{m}^{2}$ cell. The quadrat was moved along the line to cover the entire 10-m line plus an additional $2 \mathrm{~m}$ at each end of the line. A 2-m area to either side of the line was also surveyed, for a total of $84 \mathrm{~m}^{2}$ evaluated. Where necessary, seedlings were destructively sampled to count all seedlings. When seedlings occurred in clumps, sediment was gently removed to ensure an accurate count of seedlings, or in the case of large clumps, were excavated and returned to the laboratory for counting. The number of seedlings occurring individually and within clumps was recorded for each treatment.

Statistical analysis: The influence of site and seeding method on initial seedling establishment was assessed by Poisson regression. This approach is preferable to a "standard" parametric analysis of variance among treatments because the response variable represents counts of relatively rare events ( $<10$ percent of seeds germinating), which do not follow a normal distribution. The large number of observations (54,000 seeds/site) also lends well to this approach. Poisson regression has the advantage of providing an odds ratio; that is, the odds that a single seed will result in a seedling under the "test" condition (in this case, machine-planted or pipette-injected) relative to the "reference" condition (hand-broadcast), rather than simply an indication that the treatments differ. Analyses were conducted using the GENMOD procedure in SAS version 9.1 software (SAS Institute, Cary, NC), with the scale factor set to log (n).

RESULTS: Burying seeds, either with or without gel, had an overall positive effect on seedling establishment, but the effectiveness and the best method varied among sites (Figure 7). Poisson regression showed that across all sites the planting machine increased the odds of successful seedling establishment by a factor of 1.57 relative to hand-broadcast seeds, and injecting the seeds directly, without gel, increased the odds by a factor of 2.09. However, variability in physical and biological characteristics of the substrate among sites caused substantial differences in effectiveness. Individual regression models fit for each site showed no effect of method at the York River site, a 4.0-fold increase by the planting machine at the Piankatank (but no increase for hand-injected seeds), and a 2.55-fold increase for hand-injected seeds in Spider Crab Bay (but no increase for machine-planted seeds).

Clumping of seedlings occurred almost exclusively at the Spider Crab site, also the site of the highest seedling establishment rates for all treatments (Figure 8). At that site, clumping was prevalent in the pipette treatments (49.3 percent of seedlings in that treatment), rare in the broadcast treatments (3.4 percent), and absent from machine-planted plots. In the 31 clumps found, the 
mean number of seedlings per clump was $51 \pm 32.4$ SD (standard deviation), and the range was 8-142.

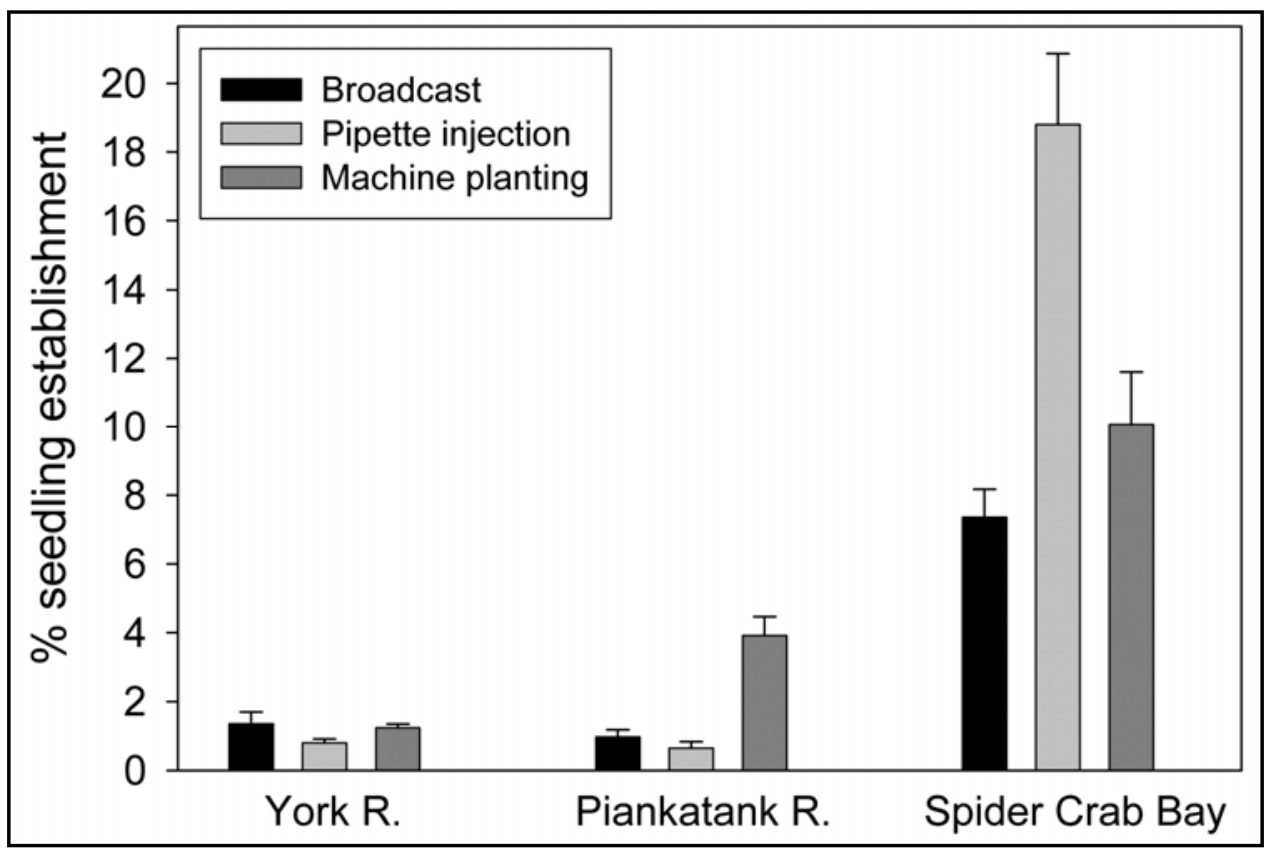

Figure 7: Mean initial seedling establishment of seeds distributed by three methods $(n=6$, error bars indicate standard error).

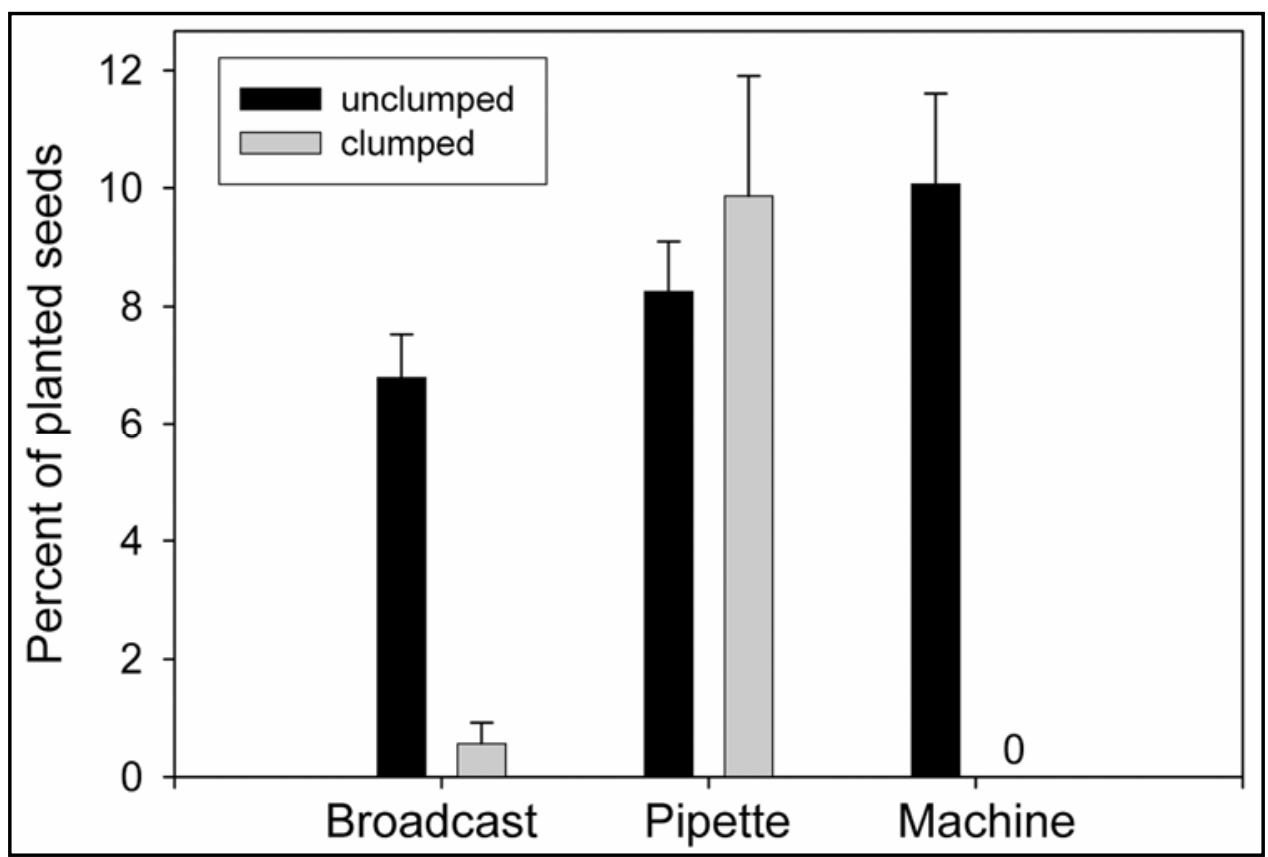

Figure 8. Mean percentage of planted seeds emerging as seedlings at low density (unclumped) or in high-density clusters presumed detrimental to survival of most seedlings at the Spider Crab Bay site $(n=6,5,6$ for broadcast, pipette, and machine, respectively. Error bars indicate standard error). 
DISCUSSION: The seed planting machine showed promise for increasing seedling establishment relative to seed broadcasting, but its effectiveness varied among the three restoration sites tested. Differences in sediment characteristics and energetic regimes at the sites may explain these patterns. The two sites with generally low seedling success (York and Piankatank) have sediments that contain a higher percentage of sand, have relatively little biogenic structure, and were both exposed to high-energy storm conditions in the late fall and winter during the early stages of seedling development. The reason for the difference in machine effectiveness between the York and Piankatank is unknown, though the slightly smaller silt/clay fraction at the Piankatank may be an important parameter, given the need for seedlings' developing root hairs and rhizomes to anchor in the sediment.

At the Piankatank, the seeds injected into the sediment by hand (without any gel) had similar success to those broadcast on the surface, while the machine-planted seeds achieved roughly four times that rate of establishment, implying that the presence of the gel, rather than simply the burial of the seeds, may have played an important role at that site. The protein-based gelatin is easily soluble in seawater, and should have dissipated quickly under field conditions, so the mechanism of any potential gel impact is unclear. Two theoretical mechanisms are proposed:

1. If buried gelatin did not disperse, and provided a source of organic material for microbial metabolism, locally lowered sediment oxygen levels could have stimulated seed germination (Moore et al. 1993).

2. Residual gel may have helped bind sediments, stabilizing the substrate in the planting tracks, which would help developing seedlings resist being scoured out by winter storm waves.

Why a similar pattern was not observed in the York is unclear, but the authors believe that the generally low seedling success at these two sites was primarily a result of high physical disturbance of developing seedlings. The two sites differ in exposure (N/NE at the Piankatank, W/SW at the York), so storm systems would be expected to impact the sites differently.

At the coastal bay site, however, the gel did not have an additional beneficial effect; instead, the machine-planted seeds underperformed those injected without gel (10 percent versus 19 percent seedling establishment), and were marginally better than broadcast seeds (8 percent). That site features softer, more cohesive sediments, much lower wave energy, rich biogenic structures (worm tubes, burrows, clams), and presumably a shallow oxygen penetration depth due to higher organic content. Loss of developing seedlings due to physical disturbance and sediment resuspension is thought to be a much less important process at this site.

The observed clumping of seedlings in hand-injected treatments may be important at the Spider Crab Bay site. For example, developing seedlings in dense clumps may be more resistant to physical disruption, or there may be some as-yet unidentified chemical cue, caused by developing 
seedlings, that enhances germination of nearby seeds. The planting machine apparently distributed seeds very evenly, with no seedling clumps found at the Spider Crab site. To determine whether the gel had any direct impact on germination at that site, further experimentation would be necessary to separate potential independent effects of clumping and gel.

The pattern of low seedling establishment rates (generally less than 10 percent, and commonly 1-5 percent) has been consistent across years and with different tests of seed dispersal timing and dispersal mechanisms (Orth et al. 2003, unpublished data). The machine planter significantly increased seedling establishment at the Piankatank site to 4 percent, where seedling establishment rates of only 1 percent or less in previous years (Harwell and Orth 1999; unpublished data). However, this low rate remains the major bottleneck in seed-based restoration projects, especially where seed supplies are limited.

The low rates of seedling establishment may be a function of spatial and temporal variability in both biotic and abiotic factors influencing seed and seedling survival once seeds are dispersed. Seeds on the sediment surface can be eaten by a variety of predators such as blue crabs, hermit crabs, and mud crabs (Wigand and Churchill 1988, Fishman and Orth 1996). Seeds could be buried at depths that do not allow successful emergence of the cotyledon (Churchill 1992). Alternatively, seeds germinating at shallow depths may be more susceptible to uprooting if roots are poorly anchored or sediments are not cohesive and are easily eroded during wintertime storms. Elucidating potential seed loss mechanisms and their variability in space and time at each site may be important in ensuring significant survival of seeds.

Another key factor that could influence seed losses is the timing of seed dispersal in relationship to seed germination, and understanding the cues that control seed germination (Orth et al. 2006b). In the Chesapeake Bay region, Z. marina seed germination appears to be temperature dependent, occurring in November and early December when water temperatures drop below $15^{\circ} \mathrm{C}$. Factors controlling seed germination include water temperature and sediment redox potential (Moore et al. 1993); germination is thought to be inhibited by oxygen. Because the depth at which sediment redox potential cues germination can vary by sediment type (e.g. coarse sandy sediments would be expected to have a different profile than silty sand), and which can also vary with temperature, the depth at which a seed is buried can also be important in seedling establishment.

One advantage of the machine planter appears to be the evenness in which seeds are dispersed and subsequently emerge. No clumping of seeds was noted in the machine treatments at the Spider Crab Bay site, the site with the highest number of established seedlings. This lack of clumping is related to how seeds are delivered and maintained on the bottom once injected by the machine planter. Seeds, which are negatively buoyant and will settle rapidly in water-filled containers (Orth et al. 1994), once mixed in the agar-based gel, remain suspended as long as the gel remains in a solid phase, and are then pumped into the bottom where they remain in the gel until 
covered by the sled. Seeds in the hand-held injector were not embedded in gel and were subject to the divers' ability to push seeds out of the syringe at a slow rate, ensuring a constant rate of seed release. At the Spider Crab site, an even rate of seed injection was not achieved, although the rate of establishment was very high. No clumping of seedlings was noted the other sites, which may have been more a result of far fewer seedlings establishing.

While survivorship of seedlings was not tracked in these clumps, field observations from other ongoing work (unpublished data), and the literature (Granger et al. 2000) suggest that only a small proportion of these clumped seedlings will actually survive and contribute to patch formation. Thus, while significantly more seedlings established in the hand-injected treatment in Spider Crab Bay, the competition among seedlings within clumps would likely reduce surviving adult plants to numbers closer to those of the machine-planted plots, where seedling competition was minimal.

POTENTIAL FOR FUTURE USE: Interest in seagrass restoration is increasing worldwide as the value of seagrass ecosystems is increasingly recognized by scientists, managers, and regulators (Orth et al. 2000, 2006b). In an attempt to minimize the labor-intensive nature of manual planting methods, mechanical methods have been developed in both the United States and Australia. These mechanical methods have primarily been developed for adult plants, and have met with varying degrees of success (Paling et al. 2001a, 2001b; Fishman et al. 2004). Each has distinct limitations in their operating procedures (e.g. depth limitations, donor bed locations, or requiring plants grown from expensive nursery operations, need for SCUBA divers, weather limitations). While seagrass seeds have had limited use in seagrass restoration programs, and have had a bottleneck in seedling establishment rates (Orth et al. 2003), seeds have been shown to be critical in natural bed recovery following disturbances (Plus et al. 2003) and in initiating recovery in systems where seed recruitment is rare (Orth et al. 2006b). By developing an efficient mechanical planter to increase the seedling establishment rate of seeds in restoration efforts, seeds could prove to be a more rapid and possibly economical method for restoring seagrass beds.

Each of the methods examined here has requirements that need to be considered in the restoration process. All methods require an efficient method of storing seeds from the collection period until dispersal. The mechanical seed planter requires an anchored second boat with an electric pull system that draws the planting machine back to the anchored boat as the seeds are being injected into the bottom. This ensures a constant delivery of seeds yielding the more even distribution of seeds. The machine planter requires a pre-made gel matrix for seed delivery; the requirement in this case was 5 gal for two 10-m lines. The gel must be kept cool during the entire process. Submerged objects such as rocks, tree stumps, or old pilings, as well as high wind conditions, can compromise the efficient operation of the planter. The broadcast method requires only one individual to disperse the seeds either underwater or from a boat, and can be conducted under more compromising wind conditions. There is little control over where seeds eventually 
settle, which will be dependent on sediment surface features (Orth et al. 1994), while seeds placed into the sediment with the mechanical planter can be more evenly spread and are not constrained by sediment features.

ACKNOWLEDGEMENTS: The authors gratefully acknowledge the contributions of Martin Wunderly and Cory Holbert during the field component of this study. Partial support of this project by NOAA's Chesapeake Bay Program Grant NA05NMF4571250 is also gratefully acknowledged.

POINTS OF CONTACT: For more information, contact Professor Robert J. Orth (jjorth@vims.edu), Department of Biological Sciences, Virginia Institute of Marine Science, School of Marine Science, College of William and Mary, Gloucester Pt., Virginia 23062; or Dr. Deborah Shafer (Deborah.J.Shafer@usace.army.mil), U.S. Army Engineer Research and Development Center, 3909 Halls Ferry Road, Vicksburg, MS 39180.

This technical note should be cited as follows:

Orth, R., S. Marion, S. Granger, and M. Traber. 2008. Restoring eelgrass (Zostera marina) from seed: A comparison of planting methods for large-scale projects. SAV Technical Notes Collection. ERDC/TN SAV-08-1. Vicksburg, MS: U.S. Army Engineer Research and Development Center.

\section{REFERENCES}

Churchill, A. C. 1992. Growth characteristics of Zostera marina seedlings under anaerobic conditions. Aquatic Botany 43: 379-392.

Fishman, J. R., and R. J. Orth. 1996. Effects of predation on Zostera marina seed abundance. Journal of Experimental Marine Biology and Ecology 198: 11-26.

Fishman, J. R., R. J. Orth, S. Marion, and J. Bieri. 2004. A comparative test of mechanized and manual transplanting of eelgrass, Zostera marina, in Chesapeake Coastal Ocean Office, Silver Spring, MD.

Fonseca, M. S., D. L. Meyer, and M. O. Hall. 1996. Development of planted seagrass beds in Tampa Bay, Florida, U.S.A. II. Faunal components. Marine Ecology Progress Series 132: 141-156.

Fonseca, M. S., W. J. Kenworthy, and G. W. Thayer. 1998. Guidelines for the conservation and restoration of seagrasses in the United States and adjacent waters. NOAA Coastal Ocean Program Decision Analysis Series No. 12. Silver Spring, MD: NOAA Coastal Ocean Office.

Granger, S. L., M. S. Traber, and S. W. Nixon. 2000. The influence of planting depth and density on germination and development of Zostera marina L. seeds. Biologia Marina Mediterranea 7:55-58.

Granger, S., M. Traber, S. W. Nixon, and R. Keyes. 2002. A practical guide for the use of seeds in eelgrass (Zostera marina L.) restoration. Part 1. Collection, processing, and storage, ed. M. Schwartz. Narragansett, RI: Rhode Island Sea Grant.

Harwell, M. C., and R. J. Orth. 1999. Eelgrass (Zostera marina L.) seed protection for field experiments and implications for large scale restoration. Aquatic Botany 64:51-61. 
Moore, K. A., R. J. Orth, and J. F. Nowak. 1993. Environmental regulation of seed germination in Zostera marina L. (eelgrass) in Chesapeake Bay: Effects of light, oxygen, and sediment burial depth. Aquatic Botany 45: 7991.

Orth, R. J., and K. A. Moore. 1983. Seed germination and seedling growth of Zostera marina L. (eelgrass) in the Chesapeake Bay. Aquatic Botany 15: 117-131.

Orth, R. J., and K. A. Moore. 1984. Distribution and abundance of submerged aquatic vegetation in Chesapeake Bay: An historical perspective. Estuaries 7: 531-540.

Orth, R. J., M. W. Luckenbach, and K. A. Moore. 1994. Seed dispersal in a marine macrophyte: Implications for colonization and restoration. Ecology 75: 1927-1939.

Orth, R. J., M. C. Harwell, E. M. Bailey, A. Bartholomew, J. T. Jawad, A. V. Lombana, K. A. Moore, J. M. Rhode, and H. E. Woods. 2000. A review of issues in seagrass seed dormancy and germination: Implications for conservation and restoration. Marine Ecology Progress Series 200: 277-288.

Orth R. J., J. R. Fishman, M. C. Harwell, and S. R. Marion. 2003. Seed density effects on germination and initial seedling establishment in eelgrass Zostera marina in the Chesapeake Bay region, USA. Marine Ecology Progress Series 250: 71-79.

Orth, R. J., M. L. Luckenbach, S. R. Marion, K. A. Moore, and D. J. Wilcox. 2006a. Seagrass recovery of in the Delmarva Coastal Bays, USA. Aquatic Botany 84: 26-36.

Orth, R. J., M. C. Harwell, and G. J. Inglis. 2006b. Ecology of seagrass seeds and dispersal strategies. In Seagrasses: Biology, ecology and conservation, ed. A. W. D. Larkum, R. J. Orth, and C. M. Duarte. The Netherlands: Springer.

Orth, R. J., J. Bieri, J. R. Fishman, M. C. Harwell, S. R. Marion, K. A. Moore, J. F. Nowak, and J. van Montfrans. 2006c. A review of techniques using adult plants and seeds to transplant eelgrass (Zostera marina L.) in Chesapeake Bay and the Virginia Coastal Bays. In Proc. Conf. Seagrass Restoration: Success, Failure, and the Costs of Both. March 11, 2003. Sarasota, Florida, Ed. S. F. Treat and R. R. Lewis, 1-17.

Paling, E. I., M. van Keulen, K. Wheeler, J. Phillips, and R. Dyhrberg. 2001a. Mechanical seagrass transplantation in western Australia. Ecological Engineering 16: 331-339.

Paling, E. I., M. van Keulen, K. Wheeler, J. Phillips, R. Dyhrberg, and D. A. Lord. 2001b. Improving mechanical seagrass transplantation. Ecological Engineering 18: 107-113.

Plus, M., J.-M. Deslous-Paoli, and F. Dagault. 2003. Seagrass (Zostera marina L.) bed recolonization after anoxiainduced full mortality. Aquatic Botany 77: 121-134.

Traber, M., S. Granger, and S. Nixon. 2003. Mechanical seeder provides alternative method for restoring eelgrass habitat (Rhode Island). Ecological Restoration 21: 213-214.

Treat, S. F. and R. R. Lewis. 2006. Seagrass restoration: Success, failure, and the costs of both. In Proc. Conf. Seagrass Restoration: Success, Failure, and the Costs of Both. March 11, 2003. Sarasota, Florida.

Wigand, C., and A. C. Churchill. 1988. Laboratory studies on Zostera marina seed and seedling predation. Estuaries 11: 180-183.

NOTE: The contents of this technical note are not to be used for advertising, publication, or promotional purposes. Citation of trade names does not constitute an official endorsement or approval of the use of such products. 